\title{
EFFECT OF EXTRACTION CONDITIONS ON PHENOLIC COMPOUNDS FROM BLACKBERRY LEAVES EXTRACTS
}

\author{
Ana Salevic ${ }^{1}$, Ana Kaluševic ${ }^{1}$, Steva Levic ${ }^{1}$, Branko Bugarski ${ }^{2}$, Viktor Nedovic ${ }^{1 *}$ \\ 1* Department of Food Technology and Biochemistry, Faculty of Agriculture, University of Belgrade, Nemanjina 6, 11080, Zemun, \\ Belgrade, Republic of Serbia, e-mail: vnedovic@agrif.bg.ac.rs \\ ${ }^{2}$ Department of Chemical Engineering, Faculty of Technology and Metallurgy, University of Belgrade, Karnegijeva 4, 11120 , \\ Belgrade, Serbia
}

\begin{abstract}
Blackberry leaves have been used as a tea substituent in many herbal mixtures. Medicinal properties of this plant material are related to a high level of components with antioxidant activity, such as phenolic compounds. The aim of the research was to evaluate the effect of different extraction conditions on the content of phenolic compounds and antioxidant activity of blackberry leaves extracts. In this study, blackberry leaves extracts were produced by an aqueous extraction procedure. Different extraction conditions: water temperature $\left(40\right.$ and $\left.80^{\circ} \mathrm{C}\right)$ and extraction time $(15$ and $30 \mathrm{~min})$ were investigated. The blackberry leaves extract prepared by applying higher temperature $\left(80^{\circ} \mathrm{C}\right)$ and longer time (30 minutes) was characterized by the highest contents of total phenolic compounds (1534.15 mg gallic acid equivalents $\left.\mathrm{L}^{-1}\right)$, flavonoids $\left(715 \mathrm{mg}\right.$ quercetin equivalents $\left.\mathrm{L}^{-1}\right)$ and flavan-3-ols (28.21 mg $(+)$-catechin $\left.\mathrm{L}^{-1}\right)$. Also, this extract expressed the highest antioxidant activity in terms of the ferric reducing ability of plasma (27.33 mmol Trolox equivalents $\mathrm{L}^{-1}$ ) and generation of 2,2'-azinobis-(3-ethylbenzothiazoline-6-sulfonic acid) radical cation (1.47 mmol Trolox equivalents $\left.\mathrm{L}^{-1}\right)$. The obtained results indicated that the produced extracts are a rich source of phenolic compounds with high antioxidant activity. Among investigated conditions, the use of water heated to higher temperature $\left(80^{\circ} \mathrm{C}\right)$ during prolonged time (30 $\mathrm{min}$ ) is the most optimal procedure for the extraction of phenolic compounds with antioxidant activity from blackberry leaves. Further research is needed to determine the exact phenolic profile and their bioavailability, as well as to develop new functional food ingredients or nutraceuticals containing blackberry leaves extracts.
\end{abstract}

Keywords: blackberry leaves, phenolic compounds, antioxidant activity, flavonoids, flavan-3-ols.

\section{Introduction}

The use of herbal remedies is widespread among different patient groups and in the general population to promote health (Holst et al, 2009). The trend of wide using and applications of herbs as herbal infusions or tea, as the common name, is preserved from traditional medicinal system to this day owing to the rich and diverse phytochemicals composition (Komes et al., 2014). The investigation of unconventional raw materials for tea preparation has gained particular interest (Melkadze et al., 2008).

Blackberry (Rubus fruticosus L.) is widely grown and processed due to its fruits with pleasant organoleptic characteristics and a high content of compounds with health beneficial effects (MikulicPetkovsek et al., 2017). In addition to fruits, blackberry leaves represent a rich complex of biologically active substances (Nikitina et al., 2000). Blackberry leaves have been used as a tea substituent or constituent of herbal mixtures for many therapeutic purposes (Melkadze et al., 2008). Namely, tea made from the blackberry leaves has been used in folk medicine for their anti-inflammatory, antiviral and antimicrobial properties, as well as antiproliferative activity (Martini et al., 2009).

Health beneficial effects are mainly attributed to phenolic compounds (Nile, Park, 2014). Furthermore, sensory properties of tea, such as taste and smell, depend on the composition and content of phenolic compounds in the raw material and the degree of their changes during tea preparation (Melkadze et al., 2008).

Blackberry leaves are known to contain high content of phenolic compounds such as ellagic acid, quercetin, kaempherol, rutin, procyanidins, (-)-catechin, caffeic acid, as well as their derivates such as ellagitannins and quercetin 3-O- $\beta$-d-glukopyranoside (Buricova et al., 2011; Gudej, Tomczyk 2004; Martini et al., 2009, Oszmiański et al., 2015, Pavlović et al., 2016). Phenolic compounds, depending on the quantitative and qualitative composition, contribute to a high antioxidant activity of blackberry leaves (Wang, Lin, 2000). The ability to subdue free radicals contributes to an important role of phenolic compounds in the prevention or delay of cancer, heart diseases and diseases of the aging process (Nile, Park, 2014). Therefore, these phytochemicals offer numerous opportunities to be used as health beneficial agents for development of new functional food products (Nile, Park, 2014). Additionally, blackberry leaves contain significant amounts of triterpenes, mineral salts and vitamin $\mathrm{C}$ (Gudej, Tomczyk, 2004).

Due to the potential health beneficial effects related to tea drinking, it is important to determine the optimal extraction conditions to obtain tea with high content of biologically active compounds and strong antioxidant activity. Therefore, the aim of this study was to evaluate the effect of different extraction conditions (water temperature and extraction time) on the content of phenolic compounds and antioxidant activity of blackberry leaves extracts.

\section{Materials and Methods}

Chemicals and Materials

All the chemicals used in this study were of analytical grade and used as such without further purification. Folin-Ciocalteu reagent and gallic acid were purchased from Merck (Darmstadt, Germany). Sodium carbonate, sodium nitrite, sodium dihydrogen phosphate, disodium hydrogen phosphate, sodium acetate, iron (III) chloride and aluminium chloride were supplied by Centrohem 
(Belgrade, Serbia). Hydrochloric acid and acetic acid were procured from Zorka (Šabas, Serbia). DPPH (2,2-dyphenyl-1-picrylhydrazyl), Trolox (6-hydroxy2,5,7,8-tetramethylchroman-2-carboxylic acid), TPTZ (2,4,6-tri(2-pyridyl)-s-triazine), ABTS (2,2'-azinobis(3-ethylbenzothiazoline-6-sulfonic acid)), potassium persulfate, sodium hydroxide, quercetin and vanillin were provided by Aldrich (Sigma-Aldrich Chemie Steinheim, Germany). Ethanol was procured from Vrenje Spiritana (Belgrade, Serbia).

Blackberry leaves (Čačanska Bestrna variety) were collected in Arilje (Western Serbia) during the full ripening stage of the fruits (July, 2015). Fully ripened leaves are more desirable concerning the phenolic compounds, since their content and antioxidant activity are decreased in old leaves (Wang, Lin, 2000). Collected leaves were healthy, uniform in the size and at the same senescence stage.

\section{Sample preparation}

Harvested leaves were air-dried at room temperature in dark. Moisture content was determined (92.3\%) according to a method approved by AOAC (Association of Official Analytical Chemists) International (AOAC, 1997). Afterwards, the dried material was ground in a laboratory mill to fine powder.

The aqueous extraction procedure was applied. The blackberry leaves $(0.5 \mathrm{~g})$ were extracted in $50 \mathrm{~mL}$ of distilled water on a magnetic stirrer. The effect of different extraction conditions: water temperature (40 and $80^{\circ} \mathrm{C}$ ) and extraction time (15 and $30 \mathrm{~min}$ ) on the content of phenolic compounds, as well as antioxidant activity of extracts was studied. After extraction, the samples were centrifuged (centrifuge model: Boeco U-320 Hamburg, Germany) at $6000 \mathrm{rpm}$ during 4 minutes.

Determination of total phenolic content (TPC)

TPC was determined according to a method with FolinCiocalteu's reagent (Singleton, Rossi, 1965). An aliquot of each extract $(0.5 \mathrm{~mL})$ was mixed with 10-fold diluted Folin-Ciocalteu's phenol reagent $(2.5 \mathrm{~mL})$ and allowed to react for 5 minutes. The sodium carbonate solution $\left(75 \mathrm{~g} \mathrm{~L}^{-1}, 2 \mathrm{~mL}\right)$ was added to the mixture and shaken. After $2 \mathrm{~h}$ of reaction at room temperature in dark, the absorbance of blue coloration was measured at $760 \mathrm{~nm}$. Gallic acid was used as the standard and the results were expressed as mg gallic acid equivalents (GAE) $\mathrm{L}^{-1}$.

\section{Determination of flavonoids content (TFC)}

TFC was assessed spectrophotometrically according to a previously published method with some modifications (Zhishen et al., 1999). The volume of $2.5 \mathrm{~mL}$ of extracts was mixed with $150 \mu \mathrm{L} 5 \% \mathrm{NaNO}_{2}$ solution and allowed to react during 6 minutes. $10 \% \mathrm{AlCl}_{3}(150 \mu \mathrm{L})$ was added and left to react for 5 minutes. Afterwards, $1 \mathrm{~mL}$ of $1 \mathrm{~mol} \mathrm{~L}^{-1} \mathrm{NaOH}$ solution and $1.2 \mathrm{~mL}$ of distilled water were added and absorbance was measured at $510 \mathrm{~nm}$. Quercetin was used as the standard and the results were expressed as mg quercetin equivalents $(\mathrm{QE}) \mathrm{L}^{-1}$.
Determination of flavan-3-ols content

The content of flavan-3-ols was estimated using the vanillin assay (Di Stefano et al., 1989). $500 \mu \mathrm{L}$ of each extract was mixed with $3 \mathrm{~mL}$ of $4 \%$ vanillin solution and allowed to react for 5 minutes. $35 \%$ chloric acid $(1.5 \mathrm{~mL})$ was added to mixture and vigorously shaken. After 15 minutes of reaction at room temperature in dark, the absorbance of red coloration was measured at $500 \mathrm{~nm}$. The amount of flavan-3-ols was calculated according to the corresponding formula based on difference between absorbance of vanillin-containing sample and blank. The results were expressed as $\mathrm{mg}(+)$-catechin equivalents $(\mathrm{CE}) \mathrm{L}^{-1}$.

Determination of DPPH radical-scavenging activity The samples were analysed according to the slightly modified previously published procedure (Sharma, Bhat, 2009). An aliquot of each extract $(0.2 \mathrm{~mL})$ was mixed with $2.8 \mathrm{~mL}$ of DPPH (2,2-diphenyl-1picrylhydrazyl) solution (mixture of $1.86^{\mathrm{x}} 10^{-4} \mathrm{~mol} \mathrm{~L}^{-1}$ $\mathrm{DPPH}^{-}$in ethanol and $0.1 \mathrm{~mol} \mathrm{~L}^{-1}$ acetate buffer $(\mathrm{pH} 4.3$ ) in volume ratio $2: 1$ ). Free radical scavenging activity was determined by measuring the absorbance of solution at $525 \mathrm{~nm}$ after 30 minutes of reaction at room temperature in dark. Trolox was used as standard and the results were expressed as mmol Trolox equivalents (TE) $\mathrm{L}^{-1}$.

Determination of ferric reducing/antioxidant power (FRAP assay)

The FRAP assay was carried out according to the published procedure with some modifications (Benzie, Strain, 1996). The FRAP solution was prepared by mixing acetate buffer (pH 3.6), TPTZ (2,4,6-tri(2-pyridiyl)-s-triazine) $\left(10 \mathrm{mmol} \mathrm{L}^{-1} \mathrm{TPTZ}\right.$ solution in $\left.40 \mathrm{mmol} \mathrm{L}^{-1} \mathrm{HCl}\right)$ and $\mathrm{FeCl}_{3} \times 6 \mathrm{H}_{2} \mathrm{O}$ $\left(5.41 \mathrm{~g} \mathrm{~L}^{-1}\right)$ in volume ratio $10: 1: 1$, respectively. Each extract $(0.1 \mathrm{~mL})$ was mixed with distilled water $(0.3 \mathrm{~mL})$ and FRAP reagent $(3 \mathrm{~mL})$. After the reaction at $37^{\circ} \mathrm{C}$ for $40 \mathrm{~min}$, the absorbance of blue coloration was measured at $593 \mathrm{~nm}$. Trolox was used as standard and the results were expressed as mmol Trolox equivalents (TE) $\mathrm{L}^{-1}$.

Determination of ABTS radical-scavenging ability

The Trolox equivalent antioxidant capacity (TEAC) of extracts was evaluated by the $\mathrm{ABTS}^{+}\left(2,2^{\prime}\right.$-azinobis(3-ethylbenzothiazoline-6-sulphonic acid)) radical cation decolorization assay ( $\mathrm{Re}$ et al., 1999). The volume of $30 \mu \mathrm{L}$ of each sample was mixed with $3 \mathrm{~mL}$ of ABTS solution. After reaction for 6 minutes the absorbance of green coloration was measured at $734 \mathrm{~nm}$. Trolox was used as standard and the results were expressed as mmol Trolox equivalents (TE) $\mathrm{L}^{-1}$.

Statistical analysis

All results were obtained in three independent measurements and expressed as mean \pm standard deviation. The experimental data were tested using Oneway analysis of variance (ANOVA) and Tukey's test in order to detect significant difference $(p<0.05)$ between the mean values. Additionally, Pearson correlation was determined between content of phenolic compounds and 
antioxidant activity. Statistical analysis was performed using the statistical program Statgraphics Centurion XV (Statpoint technologies, Virginia, USA).

\section{Results and Discussion}

The effect of different extraction conditions (water temperature 40 and $80{ }^{\circ} \mathrm{C}$ and extraction time 15 and $30 \mathrm{~min}$ ) on the content of phenolic compounds and antioxidant activity of the blackberry leaves extracts was studied.

The contents of total phenolic compounds (TPC), flavonoids (TFC) and flavan-3-ols of produced extracts are shown in Table 1. As can be seen, the highest contents of these compounds were determined when the water heated to higher temperature $\left(80^{\circ} \mathrm{C}\right)$ was used for the extraction during prolonged time $(30 \mathrm{~min})$ (1534.15 mg GAE L $\mathrm{L}^{-1}, 715.00 \mathrm{mg}$ QE $\mathrm{L}^{-1}$ and $28.21 \mathrm{mg}+(-)$-catechin $\mathrm{L}^{-1}$, respectively). Significantly higher content of total phenolic compounds in the extracts was achieved using water heated to $80^{\circ} \mathrm{C}$. At this temperature the extraction time had a significant influence on the content of these compounds which was increased with prolongation of the extraction time. Extraction of increased contents of phenolic compounds using water heated at higher temperature is in the agreement with the studies for extracts of green tea (Komes et al., 2010), raspberry leaves (Salević et al, 2016) and herbal mixture (Veljović et al., 2015). The produced extracts have higher content of total phenolic compounds compared to blackberry leaves extract prepared with phosphate buffer by centrifugation (Wang, Lin, 2000) or in deionised water at $98^{\circ} \mathrm{C}$ during $20 \mathrm{~min}$ (Buricova et al., 2011), but lower than blackberry leaves extract prepared with a mixture of methanol/ water during $1 \mathrm{~h}$ in an ultrasonic bath (Pavlović et al., 2016). Generally, the content of extracted phenolic compounds is greatly influenced by the solvent nature and numerous extraction conditions, such as $\mathrm{pH}$, temperature, solvent to solid ratio and particle size (Nour et al., 2014).
The results of this study point out that blackberry leaves extracts are a source of total flavonoids and flavan-3-ols. Content of total flavonoids was significantly increased in the extract produced in water at $80{ }^{\circ} \mathrm{C}$ during $30 \mathrm{~min}$. In the extracts prepared using water at higher temperature significantly higher content of flavan-3-ols was determined, while extraction time did not have statistically significant influence on the content of those compounds.

Generally, the chemical properties of extracts depend on the solvent type, the applied temperature and time, as well as the extraction technique (Ong, 2004). According to the results of this study, the extraction conditions have to be chosen concerning the phenolic class of interest.

The values of antioxidant activity of the blackberry leaves extracts determined by different methods are shown in Table 2. All analysed extracts expressed good ferric reducing / antioxidant power and DPPH radical scavenging activity, but weak ABTS radical scavenging activity. It has been reported that various methods for evaluation of antioxidant activity could give widely divergent results since they are based on different mechanisms (Tabart et al., 2009).

DPPH radical scavenging ability was a significantly lower in the extract prepared in the water heated to $40{ }^{\circ} \mathrm{C}$ during $15 \mathrm{~min}$ compared to the other extracts. Significantly stronger ferric reducing/antioxidant power was determined in the extracts prepared using water heated to $80^{\circ} \mathrm{C}$. At this temperature the extraction time had no a significant influence on antioxidant activity determined by FRAP assay. Therefore, the results point out to fluctuations in the antioxidant activity of all prepared extracts depending on the extraction conditions and applied assay. The results published by Wang, Lin (2000) indicated that leaf age could affect the antioxidant activity. It was also found that Rubus L. leaves have high antioxidant capacity and total phenolic content compared to their fruit tissues (Wang, Lin, 2000).

Table 1

Contents of total phenolic compounds (TPC), flavonoids (TFC) and flavan-3-ols in blackberry leaves extracts depending on extraction conditions

\begin{tabular}{|c|c|c|c|}
\hline Extraction conditions & TPC, mg GAE $\mathrm{L}^{-1}$ & TFC, mg QE $\mathrm{L}^{-1}$ & Flavan-3-ols, $\mathrm{mg}+(-)$ catechin $\mathrm{L}^{-1}$ \\
\hline $40^{\circ} \mathrm{C} / 15 \min$ & $1515.85 \pm 24.89^{\mathrm{bc}}$ & $449.00 \pm 31.84^{\mathrm{a}}$ & $12.80 \pm 0.70^{\mathrm{a}}$ \\
\hline $40{ }^{\circ} \mathrm{C} / 30 \mathrm{~min}$ & $1487.40 \pm 4.98^{\mathrm{ab}}$ & $621.00 \pm 2.45^{\mathrm{b}}$ & $13.67 \pm 0.63^{\mathrm{a}}$ \\
\hline $80{ }^{\circ} \mathrm{C} / 15 \mathrm{~min}$ & $1458.94 \pm 18.26^{\mathrm{a}}$ & $616.00 \pm 26.13^{\mathrm{b}}$ & $26.75 \pm 0.96^{\mathrm{b}}$ \\
\hline $80^{\circ} \mathrm{C} / 30 \mathrm{~min}$ & $1534.15 \pm 13.28^{c}$ & $715.00 \pm 15.51^{\mathrm{c}}$ & $28.21 \pm 1.17^{\mathrm{b}}$ \\
\hline
\end{tabular}

Data represent mean \pm standard deviation.

Within the same column, values followed by different letters are significantly different (Tukey's test, $\mathrm{p}<0.05$ ).

\section{Antioxidant activity of blackberry leaves extracts depending on extraction conditions} determined by DPPH, FRAP and ABTS assays

\begin{tabular}{cccc}
\hline Extraction conditions & DPPH, mmol TE $\mathbf{L}^{-\mathbf{1}}$ & FRAP, mmol TE L $^{-1}$ & ABTS, mmol TE L $^{-1}$ \\
\hline $40^{\circ} \mathrm{C} / 15 \mathrm{~min}$ & $14.29 \pm 0.00^{\mathrm{a}}$ & $23.26 \pm 0.08^{\mathrm{a}}$ & $1.47 \pm 0.09^{\mathrm{c}}$ \\
$40^{\circ} \mathrm{C} / 30 \mathrm{~min}$ & $15.05 \pm 0.13^{\mathrm{b}}$ & $26.31 \pm 0.26^{\mathrm{b}}$ & $1.15 \pm 0.07^{\mathrm{a}}$ \\
$80^{\circ} \mathrm{C} / 15 \mathrm{~min}$ & $14.93 \pm 0.06^{\mathrm{b}}$ & $27.04 \pm 0.45^{\mathrm{c}}$ & $1.30 \pm 0.06^{\mathrm{ab}}$ \\
$80^{\circ} \mathrm{C} / 30 \mathrm{~min}$ & $14.91 \pm 0.10^{\mathrm{b}}$ & $27.33 \pm 0.16^{\mathrm{c}}$ & $1.47 \pm 0.08^{\mathrm{bc}}$ \\
\hline
\end{tabular}

Data represent mean \pm standard deviation.

Within the same column, values followed by different letters are significantly different (Tukey's test, $\mathrm{p}<0.05$ ). 
Significant positive correlations were found between the results of antioxidant activity (DPPH radical scavenging activity and ferric reducing/antioxidant power) and total flavonoids (Pearson correlation $=0.8171$ and 0.8981 , respectively). Study published by Oszmiański et al. (2015) showed that phenolic compounds of high molecular weight, primarily ellagitannins, are major contributors to antioxidant activity in leaves of Rubus L. species.

According to the results of this study investigated conditions are suitable for production of extracts with high content of phenolic antioxidants. Using water as a solvent is acceptable since aqueous extraction simulates tea production and there is no need for evaporation and removing of potentially harmful solvents. Further research is needed in order to evaluate the effect of extraction conditions on the qualitative and quantitative composition of bioactive compounds.

\section{Conclusions}

The different extraction conditions (water temperature: 40 and $80{ }^{\circ} \mathrm{C}$ and extraction time: 15 and $30 \mathrm{~min}$ ) were compared on the basis of the content of phenolic compounds and antioxidant activity of blackberry leaves aqueous extracts. This study indicates that blackberry leaves extracts are the rich source of phenolic antioxidants. The highest phenolic content and antioxidant activity were obtained in the extract prepared using water at higher temperature during prolonged time.

Among investigated conditions, the use of water heated to higher temperature $\left(80{ }^{\circ} \mathrm{C}\right)$ during prolonged time (30 $\mathrm{min}$ ) is the most optimal procedure for the extraction of phenolic compounds with antioxidant activity from blackberry leaves.

It is very important to determine the content and pharmacological properties of each phenolic compound in the prepared extracts since individual compounds have different antioxidant and health properties. Therefore, further research is needed to determine the exact phenolic profile, their bioavailability and health benefits of the extracts. Also, protective mechanisms should be investigated in order to maintain those compounds active during food processing and storage and enable their delivery to the target site in an organism.

\section{Acknowledgment}

This work is supported by the Serbian Ministry of Education, Science and Technological Development (National Project No. III46010).

\section{References}

1. AOAC (1997) Official Methods of Analysis, 16th Edition, $3 r d$ revision. AOAC International, Gaithersburg, MD.

2. Benzie I.F., Strain J.J. (1996) The ferric reducing ability of plasma (FRAP) as a measure of "antioxidant power": the FRAP assay. Analytical Biochemistry, Vol. 239 (1), p. 70-76.
3. Buricova L., Andjelkovic M., Cermakova A., Reblova Z., Jurcek O., Kolehmainen, E., Verhe R., Kvasnicka F. (2011) Antioxidant capacities and antioxidants of strawberry, blackberry and raspberry leaves. Czech Journal of Food Sciences, Vol. 29 (2), p. $181-189$.

4. Di Stefano R., Cravero M.C., Gentilini, N. (1989) Metodi per lo studio dei polifenoli dei vini. L'Enotecnico, Vol. 25, p. 83-89.

5. Gudej J., Tomczyk M. (2004) Determination of flavonoids, tannins and ellagic acid in leaves from Rubus L. species. Archives of Pharmacal Research, Vol. 27 (11), p. 1114-1119.

6. Holst L., Haavik S., Nordeng H. (2009) Raspberry leaf Should it be recommended to pregnant women? Complementary Therapies in Clinical Practice, Vol. 15 (4), p. 204-208.

7. Komes D., Belščak-Cvitanović A., Ljubičić I., Durgo K., Cindrić I.J., Bušić A., Vojvodić A. (2014) Formulating blackberry leaf mixtures for preparation of infusions with plant derived sources of sweeteners. Food Chemistry, Vol. 151, p. 385-393.

8. Komes D., Horžić D., Belščak A., Ganić K.K., Vulić I. (2010) Green tea preparation and its influence on the content of bioactive compounds. Food Research International, Vol. 43 (1), p. 167-176.

9. Martini S., D’Addario C., Colacevich A., Focardi S., Borghini F., Santucci A., Figura N., Rossi C. (2009) Antimicrobial activity against Helicobacter pylori strains and antioxidant properties of blackberry leaves (Rubus ulmifolius) and isolated compounds. International Journal of Antimicrobial Agents, Vol. 34 (1), p. 50-59.

10. Melkadze R.G., Chikovani N.S., Kakhniashvili E.Z. (2008) Characteristics of the composition of caucasian blackberry (Rubus caucasicus L.) leaves as a raw material for tea production. Applied Biochemistry and Microbiology, Vol. 44 (6), p. 647-651.

11. Mikulic-Petkovsek M., Koron D., Zorenc Z., Veberic R. (2017) Do optimally ripe blackberries contain the highest levels of metabolites? Food Chemistry, Vol. 215, p. 41-49.

12. Nikitina V.S., Gerchikov A.Y., Efimenko N.B. (2000) Flavonoids from raspberry and blackberry leaves and their antioxidant activities. Pharmaceutical Chemistry Journal, Vol. 34 (11), p. 596-598.

13. Nile S.H., Park S.W. (2014) Edible berries: Bioactive components and their effect on human health. Nutrition, Vol. 30 (2), p. 134-144.

14. Nile S.H., Park S.W. (2014) Edible berries: Bioactive components and their effect on human health. Nutrition, Vol. 30, No. 2, p. 134-144.

15. Nour V., Trandafir I., Cosmulescu S. (2014) Antioxidant capacity, phenolic compounds and minerals content of blackcurrant (Ribes nigrum L.) leaves as influenced by harvesting date and extraction method. Industrial Crops and Products, Vol. 53, p. 133-139.

16. Ong E.S. (2004) Extraction methods and chemical standardization of botanicals and herbal preparations. Journal of Chromatography B, Vol. 812 (1), p. 23-33.

17. Oszmiański J., Wojdyło A., Nowicka P., Teleszko M., Cebulak T., Wolanin M. (2015) Determination of phenolic compounds and antioxidant activity in leaves from wild Rubus L. species. Molecules, Vol. 20 (3), p. 4951-4966.

18. Pavlović A.V., Papetti A., Zagorac D.Č.D., Gašić U.M., Mišić D.M., Tešić Ž.L., Natić M.M. (2016) Phenolics composition of leaf extracts of raspberry and blackberry 
cultivars grown in Serbia. Industrial Crops and Products, Vol. 87, p. 304-314.

19. Re R., Pellegrini N., Proteggente A., Pannala A., Yang M., Rice-Evans C. (1999) Antioxidant activity applying an improved ABTS radical cation decolorization assay. Free Radical Biology and Medicine, Vol. 26 (9), p. 1231-1237.

20. Salević A., Kalušević A., Nedović V. (2016) Influence of extractiom conditions on bioactive profile of raspberry leaves. In: The $3^{\text {rd }}$ International Congress „Food Technology, Quality and Safety" Congress Proceeding, Serbia, Novi Sad, p. 106-112.

21. Sharma O.P., Bhat T.K. (2009) DPPH antioxidant assay revisited. Food Chemistry, Vol. 113 (4), p. 1202-1205.

22. Singleton V.L., Rossi J.A. (1965) Colorimetry of total phenolics with phosphomolybdic-phosphotungstic acid reagents. American Journal of Enology and Viticulture, Vol. 16 (3), p. 144-158.

23. Tabart J., Kevers C., Pincemail J., Defraigne J.O., Dommes J. (2009) Comparative antioxidant capacities of phenolic compounds measured by various tests. Food Chemistry, Vol. 113 (4), p. 1226-1233.

24. Veljović M., Kalušević A., Salević A., StamenkovićĐoković M., Vukosavljević P., Bugarski B., Nedović V. (2015) Optimization of herbs extraction for soft drink production. In: The $6^{\text {th }}$ International Scientific Agricultural Symposium "Agrosym 2015" Book of Proceedings, Bosnia and Herzegovina, Jahorina, p. 478-483.

25. Wang S.Y., Lin H.S. (2000) Antioxidant activity in fruits and leaves of blackberry, raspberry, and strawberry varies with cultivar and developmental stage. Journal of Agricultural and Food Chemistry, Vol. 48 (2), p. 140-146. 26. Zhishen J., Mengcheng T., Jianming W. (1999) The determination of flavonoid contents in mulberry and their scavenging effects on superoxide radicals. Food Chemistry, Vol. 64 (4), p. 555-559. 